\title{
Refractory Primary Amyloidosis
}

National Cancer Institute

\section{Source}

National Cancer Institute. Refractory Primary Amyloidosis. NCI Thesaurus. Code C133731.

Primary amyloidosis that does not respond to treatment. 